\title{
Genome Sequencing and Transposon Mutagenesis of Burkholderia seminalis TC3.4.2R3 Identify Genes Contributing to Suppression of Orchid Necrosis Caused by B. gladioli
}

\author{
Welington L. Araújo, ${ }^{1}$ Allison L. Creason, ${ }^{2,3}$ Emy T. Mano, ${ }^{1}$ Aline A. Camargo-Neves, ${ }^{1,4}$ \\ Sonia N. Minami, ${ }^{4}$ Jeff $\mathrm{H}$. Chang, ${ }^{2,3,5}$ and Joyce E. Loper ${ }^{2,3,6}$ \\ ${ }^{1}$ Laboratory of Molecular Biology and Microbial Ecology, Department of Microbiology, Institute of Biomedical Science, University \\ of São Paulo, São Paulo, Brazil; ${ }^{2}$ Department of Botany and Plant Pathology; and ${ }^{3}$ Molecular and Cellular Biology Program, \\ Oregon State University, Corvallis, OR, U.S.A.; ${ }^{4}$ Interdisciplinary Center for Biotechnology, University of Mogi das Cruzes, Mogi \\ das Cruzes, Brazil; ${ }^{5}$ Center for Genome Research and Biocomputing, Oregon State University; and ${ }^{6}$ USDA-Agricultural \\ Research Service, Horticultural Crops Laboratory, Corvallis, Oregon, U.S.A.
}

Submitted 29 February 2016. Accepted 1 March 2016.

From a screen of 36 plant-associated strains of Burkholderia spp., we identified 24 strains that suppressed leaf and pseudobulb necrosis of orchid caused by $B$. gladioli. To gain insights into the mechanisms of disease suppression, we generated a draft genome sequence from one suppressive strain, TC3.4.2R3. The genome is an estimated 7.67 megabases in size, with three replicons, two chromosomes, and the plasmid pC3. Using a combination of multilocus sequence analysis and phylogenomics, we identified TC3.4.2R3 as B. seminalis, a species within the Burkholderia cepacia complex that includes opportunistic human pathogens and environmental strains. We generated and screened a library of 3,840 transposon mutants of strain TC3.4.2R3 on orchid leaves to identify genes contributing to plant disease suppression. Twelve mutants deficient in suppression of leaf necrosis were selected and the transposon insertions were mapped to eight loci. One gene is in a $w c b$ cluster that is related to synthesis of extracellular polysaccharide, a key determinant in bacterial-host interactions in other systems, and the other seven are highly conserved among Burkholderia spp. The fundamental information developed in this study will serve as a resource for future research aiming to identify mechanisms contributing to biological control.

The genus Burkholderia, a member of the Betaproteobacteria, consists of more than 60 species, many of which are distributed worldwide, colonizing many environmental habitats such as water, soil, and plants. Some Burkholderia species are plant

This whole-genome shotgun project has been deposited at DDBJ/EMBL/ GenBank database under accession LAEU00000000. The version described in this paper is version LAEU01000000. The sequences of the ordered contigs, GenBank-formatted files, and nucleotide as well amino acid sequences are available from the Oregon State University Scholar's Archive website.

Corresponding author: W. L. Araújo; Telephone +55 113091 7346; E-mail: wlaraujo@usp.br

*The $\boldsymbol{e}$-Xtra logo stands for "electronic extra" and indicates that seven supplementary figures and three supplementary tables are published online.

(c) 2016 The American Phytopathological Society pathogens and, collectively, these species cause disease on a wide variety of plants of importance in agriculture, landscapes, or natural ecosystems (Compant et al. 2008). One phytopathogenic species, Burkholderia gladioli, was first described as a pathogen of Gladiolus spp. (McCulloch 1921) and was later found to cause disease in many other plant species, such as rice (Ura et al. 2006), onion (Lee et al. 2005), and orchids (Keith et al. 2005; Mano et al. 2015). Other strains of Burkholderia spp. are beneficial toward plants, suppressing plant diseases and promoting plant growth through a variety of processes, such as inhibiting plant pathogens or inducing pathogen resistance, nitrogen fixation, or nutrient uptake in the host plant (Compant et al. 2008; Suárez-Moreno et al. 2012). These beneficial strains of Burkholderia spp. may be free-living or endophytic, forming mutualistic associations with the host plant (Compant et al. 2008). Burkholderia species can also cause human diseases, including devastating pulmonary infections of patients with cystic fibrosis (Drevinek and Mahenthiralingam 2010).

Phylogenetic analysis of Burkholderia spp. has revealed a division of the genus into two main clusters, the first cluster composed of the human pathogens, plant pathogens, as well as many environmental strains and the second cluster composed of exclusively environmental strains (Sawana et al. 2014; SuárezMoreno et al. 2012). A new genus designation, Paraburkholderia, has been proposed for species falling into the second cluster (Sawana et al. 2014). The first cluster includes the B. cepacia complex, which consists of at least 17 species (Vial et al. 2011). These species comprise clinical strains that cause opportunistic infections in immunocompromised humans (Agnoli et al. 2012; Vandamme and Dawyndt 2011) and environmental strains that produce antifungal compounds (Kang et al. 1998; Lu et al. 2009; Schmidt et al. 2009), suppress plant diseases (Coenye and Vandamme 2003; Parke and Gurian-Sherman 2001), and promote plant growth (Chiarini et al. 1998; Vial et al. 2011). Moreover, certain species within the B. cepacia complex cause rots of onion (Jacobs et al. 2008), banana (Lee and Chan 2007), oyster mushrooms (Yara et al. 2006), and apricot (Fang et al. 2009, $\mathrm{Li}$ et al. 2010). Distinguishing pathogenic from nonpathogenic strains within the B. cepacia complex has been an objective of much research over the past decades (Vandamme and Dawyndt 2011). Most recently, comparative genomics has provided insights into the shared and unique features of strains within the B. cepacia 
complex, and the genomes of many strains have been sequenced (Sawana et al. 2014). The genomes of B. cepacia complex species are composed of three replicons, as described for $B$. cenocepacia strains J2315 (Holden et al. 2009), H111 (Carlier et al. 2014), and AU 1054 (Yuan et al. 2014). Chromosomes 1 and 2 are conserved among all members of the B. cepacia complex group, but the third replicon, plasmid pC3, is less conserved (Carlier et al. 2014). According to Agnoli et al. (2012), pC3 is not an essential element, but encodes specific traits, such as virulence, stress resistance, antifungal activity, and exopolysaccharide production specific to the lifestyle of the strain. Horizontal gene transfer (HGT) has contributed to the evolution of the genome structure in the B. cepacia complex, allowing adaptation to the varied niches occupied by this diverse group of bacteria (Holden et al. 2009).

In this study, we evaluated strains of Burkholderia spp. that were isolated from the rhizosphere or internal tissues of sugarcane (Luvizotto et al. 2010) for the capacity to suppress orchid leaf necrosis caused by B. gladioli. This bacterial phytopathogen infects leaves and pseudobulbs of orchids of many genera, causing dark green to brown lesions surrounded by water soaking, which, in high humidity or young plants, may expand rapidly to cause necrosis of the entire leaf or pseudobulb (Keith et al. 2005; Mano et al. 2015). Bacterial leaf and pseudobulb necrosis caused by $B$. gladioli is an important constraint to orchid production in Brazil (Mano et al. 2015). Many of the strains of Burkholderia that we tested were effective in the biological control of this disease. We selected one

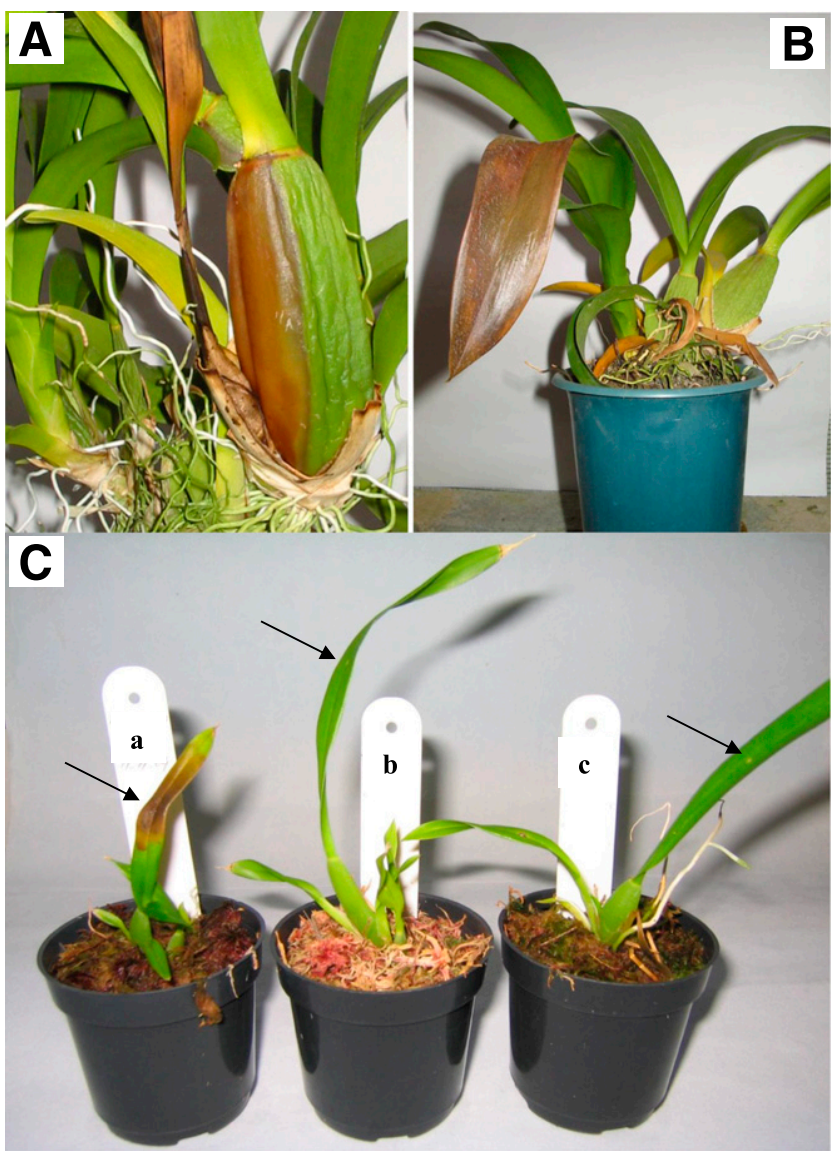

Fig. 1. Symptoms of orchid necrosis caused by Burkholderia gladioli in A, pseudobulbs and B, leaves of Oncidium flexuosum 'Aloha Iwanaga'. C, Suppression of leaf necrosis. The leaves were inoculated with $B$. gladioli (a), B. seminalis TC3.4.2R3 (b), or B. seminalis TC3.4.2R3 and B. gladioli (c). Symptoms were observed 5 days after inoculation. Arrows indicate the inoculation site. strain, TC3.4.2R3, which suppressed the disease on several orchid species, and found it to be a member of $B$. seminalis, a species within the B. cepacia complex that includes strains isolated from both clinical and environmental sources (Vanlaere et al. 2008). Certain strains of $B$. seminalis cause apricot fruit rot (Fang et al. 2009), but others are known to be beneficial to plants through biological control (Li et al. 2011, 2014), enhancing nutrient utilization by the plant (Young et al. 2013) or reducing aluminum toxicity in soil (Panhwar et al. 2015). To date, however, the genetic determinants of these beneficial functions are unknown. As a first step toward understanding the mechanisms by which B. seminalis TC3.4.2R3 suppresses orchid leaf necrosis, we sequenced the genome of the strain, generated a transposon mutant library, screened the mutant library for suppression of orchid necrosis, identified mutants deficient in biological control, and mapped the transposon insertions to eight genes in the TC3.4.2R3 genome. Although B. seminalis may not be suitable for use as a biocontrol agent due to its similarity to opportunistic human pathogens in the B. cepacia complex group, the present results can guide future research seeking to identify molecular mechanisms underpinning the interactions between Burkholderia species in the host plant.

\section{RESULTS AND DISCUSSION}

\section{Identification of Burkholderia spp. strains}

that suppress orchid leaf necrosis caused by $B$. gladioli.

Thirty-six strains of Burkholderia spp. isolated from the rhizosphere or internal tissues of sugarcane (Luvizotto et al. 2010) were screened for the suppression of leaf necrosis of orchid caused by $B$. gladioli. Each strain was inoculated into a wound on leaves of Oncidium flexuosum cultivar Aloha Iwanaga along with a pathogenic strain of B. gladioli and inoculated leaves were observed for symptoms over several days. When inoculated with B. gladioli alone, leaves of 'Aloha Iwanaga' exhibited necrosis following 5 days of incubation (Fig. 1). A total of 24 of the 36 strains of Burkholderia spp. isolated from sugarcane suppressed leaf necrosis; no necrosis was observed on leaves coinoculated with B. gladioli and any of the 24 strains (Table 1). The other 12 strains of Burkholderia spp. did not suppress leaf necrosis in this assay. The success of this screen in identifying effective bacterial antagonists contrasts with the results from an earlier screen evaluating more than 500 bacterial strains isolated from healthy orchid leaves and pseudobulbs; none of those strains were effective in suppressing leaf or pseudobulb necrosis of orchid (W. L. Araújo, unpublished data).

We also screened the 36 sugarcane strains for sensitivity to kanamycin and antagonism against $B$. gladioli in culture, to identify a strain with characteristics amenable to genetic manipulation and facile screening of biocontrol traits (Table 1). We observed no correlation between the ability of a strain to inhibit $B$. gladioli in culture and to suppress orchid necrosis. Based on these assays, we focused attention on strain TC3.4.2R3, which inhibited growth of $B$. gladioli in plate assays and is more sensitive to kanamycin than many other strains tested (Table 1). To better understand the mechanisms related to disease suppression, we inoculated the suppressive TC3.4.2R3 strain in a leaf and, after $24 \mathrm{~h}$, inoculated distal leaves with the pathogen B. gladioli. We observed no suppression of orchid necrosis in these experiments, suggesting that $B$. seminalis TC3.4.2R3 did not induce systemic disease resistance in the orchid plants.

We then set out to determine if strain TC3.4.2R3 could suppress leaf necrosis on different taxa of orchids. Of the three additional genera of orchids that were tested, strain TC3.4.2R3 suppressed disease symptoms caused by $B$. gladioli in a 
Phalaenopsis sp. and a Cattleya sp. (Fig. 2). Strain TC3.4.2R3 did not suppress disease symptoms on a Miltonia sp. These results demonstrated that the strain is effective in suppressing disease of some, but not all, orchid species. Reasons for this variation among orchid species are unknown, but the influence of host genotype on plant disease suppression has also been previously reported in other pathosystems (Ryan et al. 2004; Smith et al. 1999). The results also confirmed that strain TC3.4.2R3 is not pathogenic to any of the orchid species evaluated (Fig. 2).

We also determined the inoculum density of strain TC3.4.2R3 that was required for inhibition of disease symptoms. Suppression of disease was observed when the wounded leaf was inoculated with TC3.4.2R3 at 500 CFU per wound, a density identical to that of the coinoculated pathogen (Fig. 2). We also inoculated leaf wounds with strain TC3.4.2R3 at 50 or $5 \mathrm{CFU}$ per wound, cell densities of 0.1 or 0.01 that of the coinoculated pathogen. At these low inoculum densities, strain TC3.4.2R3 did not suppress leaf necrosis on any of the orchid species evaluated (Fig. 2). These results establish the importance of inoculum density of the antagonist in suppression of orchid necrosis, which is in line with the dose-response relationships established in previous studies evaluating the suppression of other plant diseases (Bull et al. 1991; Johnson and DiLeone 1999).

\section{Whole-genome sequencing and general genome features.}

To facilitate studies to identify genes that contribute to interactions between the two Burkholderia spp., we generated a draft genome sequence of strain TC3.4.2R3. We used a Genome Sequencer FLX 454 Titanium (Roche) and generated 640,383 reads that totaled $298,368,882$ nucleotides. The reads were de novo assembled into 84 contigs. The genome size was estimated to be $7,674,286$ base pairs with an average $\mathrm{G}+\mathrm{C}$ content of $67.22 \%$. The annotated genome sequence of TC3.4.2R3 was predicted to have 6,917 coding sequences, of which 5,784 could be assigned to a Clusters of Orthologous Genes (COG) category (Supplementary Fig. S1). Consistent with other bacteria with relatively large genomes, the genome sequence of TC3.4.2R3 had high representation in COG such as "Energy production and conversion", "Amino acid transport and metabolism", and "Transcription". There is also a high representation in the categories of "General function" and "Function unknown."

We compared the genome sequence of strain TC3.4.2R3 to the genome sequences of representative Burkholderia species (Supplementary Table S1). To put this comparison in a phylogenetic context, we concatenated the translated sequences from 1,055 genes with homologs in 12 strains and the outgroup Ralstonia solanacearum GMI1000 and constructed a neighbor-joining tree (Fig. 3A). This analysis showed that strain TC3.4.2R3 falls within the B. cepacia complex) but is distinct from other sequenced strains within this group. To further explore the taxonomic placement of strain TC3.4.2R3, we used multilocus sequence analysis (MLSA) based on seven genes (recA, atpD, gltB, gyrB, lepA, phaC, and trpB) previously validated for analysis of members of the $B$. cepacia complex (Baldwin et al. 2005). In this analysis, strain TC3.4.2R3 fell into a well-supported clade within the $B$. cepacia complex that is composed of Burkholderia seminalis strains (Fig. 3B; Supplementary Fig. S2). Strains of B. seminalis have been isolated from diverse ecological niches, including immunocompromised humans, soil, and plants (Vanlaere et al. 2008). Certain strains are known to suppress plant disease. For example, the strain $B$. seminalis $\mathrm{R} 456$, which was isolated from the rice rhizosphere, can reduce the incidence and severity of rice sheath blight under greenhouse conditions ( $\mathrm{Li}$ et al. 2011). The species includes strains with oil-emulsifying abilities (Huang et al. 2012) and strains that cause rot of apricot fruit (Fang et al. 2009; Li et al. 2010). Strain TC3.4.2R3 fell into one of the two subclades of B. seminalis, along with strains isolated from soil, sugarcane, and cystic fibrosis patients (Vanlaere et al. 2008). A second subclade includes the apricot pathogens (Fig. 3B). Our results provide convincing evidence that strain TC3.4.2R 3 is a member of the species $B$. seminalis.

We next used a reciprocal best BLASTp analysis to identify genes that are shared with 13 representative strains of Burkholderia spp. More than 2,750 clusters of homologous genes are present in all Burkholderia strains that we examined. Consistent with the whole genome-based taxonomy, B. seminalis TC3.4.2R3 had the highest level of inferred orthology with strains J2315, MC0-3, AU1054, and HI2424 of B. cenocepacia (Fig. 4). Of the 13 strains of Burkholderia species included in this comparison, B. cenocepacia $\mathrm{J} 2315$ is most similar to B. seminalis TC3.4.2R3, so we used the genome sequence of strain $\mathrm{J} 2315$ as a reference to reorder the contigs larger than 500 bp (Fig. 5).

HGT has the potential to innovate genomes and may have contributed to the ability of $B$. seminalis TC3.4.2R 3 to colonize plants and suppress bacterial necrosis of orchid. To identify regions potentially acquired via HGT, we used the software program Alien Hunter to detect recently acquired genomic regions (Vernikos and Parkhill 2006). A total of 84 regions were identified that exceeded Alien Hunter's self-defined threshold

Table 1. Strains of Burkholderia spp. isolated from sugarcane ${ }^{\mathrm{y}}$ and their isolation site, inhibitory profile, and minimal inhibitory concentration (MIC) for kanamycin

\begin{tabular}{|c|c|c|c|c|}
\hline Strains & $\begin{array}{c}\text { Isolation } \\
\text { source }\end{array}$ & $\begin{array}{l}\text { Inhibition of } \\
\text { B. gladioli in } \\
\text { culture }^{\mathrm{z}}\end{array}$ & $\begin{array}{c}\text { Suppression } \\
\text { of orchid } \\
\text { necrosis }\end{array}$ & $\begin{array}{c}\text { MIC } \\
\left(\mu \mathrm{g} \mathrm{ml}^{-1}\right)\end{array}$ \\
\hline CV2.4.3R2 & Endophyte & - & + & $>200$ \\
\hline CV3.1.1F1 & Endophyte & - & + & 200 \\
\hline CV3.2.2F5 & Endophyte & - & + & $>200$ \\
\hline ESR63 & Endophyte & - & + & $>200$ \\
\hline TC3.3.1R6 & Endophyte & - & - & $>200$ \\
\hline TC3.3.1R6 & Endophyte & + & - & 100 \\
\hline $\mathrm{TC} 3.4 .1 \mathrm{~F} 2$ & Endophyte & - & + & $>200$ \\
\hline TC3.4.1F4 & Endophyte & + & + & $>200$ \\
\hline TC3.4.1R1 & Endophyte & + & + & $>200$ \\
\hline TC3.4.2R1 & Endophyte & - & + & $>200$ \\
\hline TC3.4.2R2 & Endophyte & - & + & $>200$ \\
\hline TC3.4.2R3 & Endophyte & + & + & 100 \\
\hline TH3.1.1R4 & Endophyte & - & + & 200 \\
\hline TH3.4.1R4 & Endophyte & - & + & $>200$ \\
\hline TH2.4.1R1 & Endophyte & + & + & $>200$ \\
\hline TH2.1.3R2 & Endophyte & - & - & $>200$ \\
\hline TH2.2.3R3 & Endophyte & + & + & $>200$ \\
\hline TH2.3.3R4 & Endophyte & - & + & $>200$ \\
\hline ESR73 & Rhizosphere & - & + & $>200$ \\
\hline CV2.1.2R2 & Rhizosphere & - & - & $>200$ \\
\hline CV2.1.3F5 & Rhizosphere & + & - & $>200$ \\
\hline CV2.2.2F2 & Rhizosphere & - & - & 50 \\
\hline CV2.3.2F1 & Rhizosphere & - & - & $>200$ \\
\hline CV3.1.2F4 & Rhizosphere & - & - & $>200$ \\
\hline CV3.3.3F2 & Rhizosphere & - & - & 50 \\
\hline CV4.4.2F2 & Rhizosphere & + & + & $>200$ \\
\hline $\mathrm{TC} 2.2 .2 \mathrm{~F} 4$ & Rhizosphere & - & + & $>200$ \\
\hline $\mathrm{TC} 2.2 .2 \mathrm{~F} 5$ & Rhizosphere & - & - & $>200$ \\
\hline $\mathrm{TC} 3.3 .1 \mathrm{~F} 1$ & Rhizosphere & - & - & $>200$ \\
\hline TC3.3.3F1 & Rhizosphere & + & + & $>200$ \\
\hline $\mathrm{TC} 4.3 .1 \mathrm{~F} 2$ & Rhizosphere & - & - & $>200$ \\
\hline TH2.3.2F5 & Rhizosphere & + & + & $>200$ \\
\hline TH2.3.3R3 & Rhizosphere & - & + & $>200$ \\
\hline TH3.3.2F5 & Rhizosphere & - & + & $>200$ \\
\hline TH3.1.3F3 & Rhizosphere & + & + & $>200$ \\
\hline TH4.4.3.F1 & Rhizosphere & - & + & 50 \\
\hline
\end{tabular}

\footnotetext{
$\mathrm{y}$ Isolation of the strains is described by Luvizotto et al. 2010.

$\mathrm{z}_{-}=$no inhibition; $+=2$ - to $3-\mathrm{mm}$ inhibition halo in antibiosis assays done on tryptic soy agar.
} 
score (Fig. 5; Supplementary Table S2). Alien Hunter uses an interpolated variable order motifs method to detect regions based on differences in compositional biases (Vernikos and Parkhill 2006). It is highly sensitive but, also, prone to a higher false positive rate. Thus, we focused on the 21 regions that scored in the top $25 \%$ of the list. The regions ranged in size from 7.5 to $90 \mathrm{~kb}$ and averaged $18.9 \mathrm{~kb}$. The annotated functions for many of the 314 genes in these regions were consistent with the hypothesis that the 21 regions were acquired via HGT (Supplementary Table S3). A total of 28 genes have annotated functions associated with mobile elements, including phage proteins, integrases, transposases, restriction endonucleases, and toxin-antitoxin systems. In addition, 147 of the 314 genes are annotated as hypothetical proteins, consistent with the abundance of genes in the COG category "Function unknown". Moreover, genes associated with the top $25 \%$ of the scoring

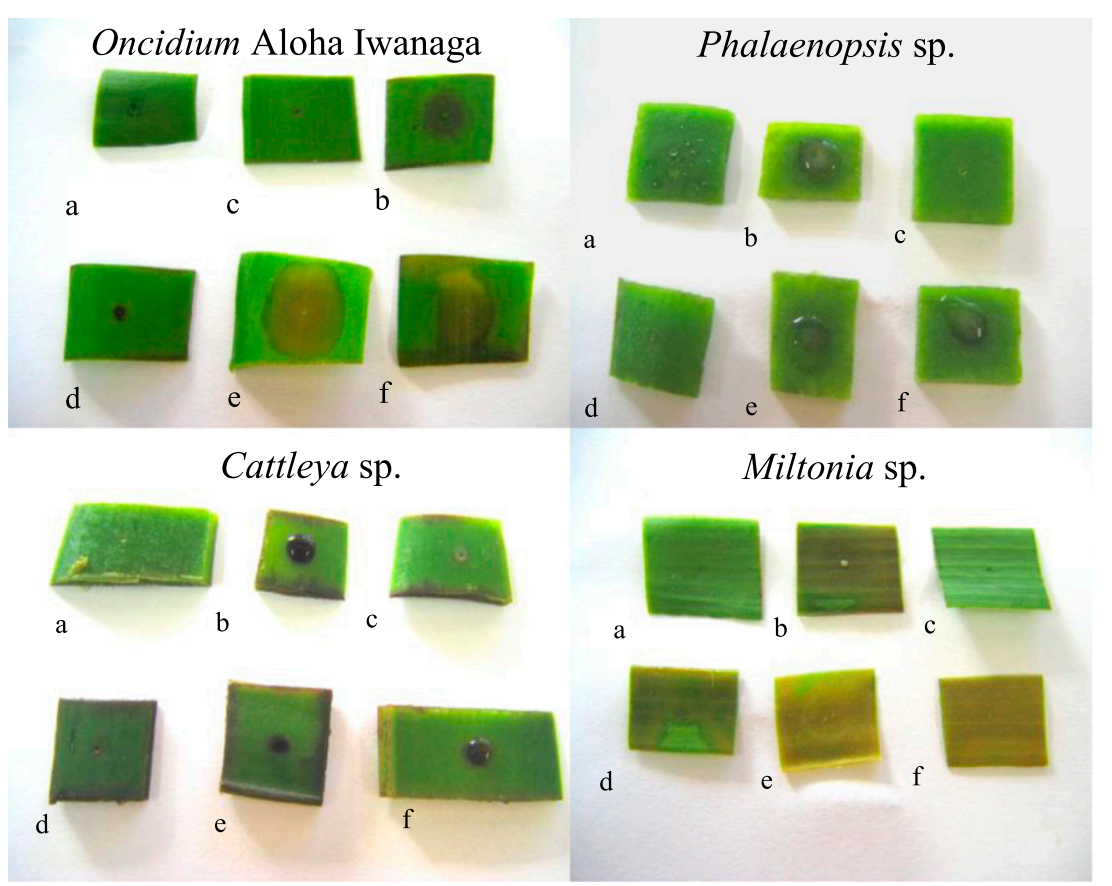

Fig. 2. Symptoms of necrosis caused by Burkholderia gladioli in leaf fragments of Oncidium flexuosum 'Aloha Iwanaga', Phalaenopsis sp., Cattleya sp., and Miltonia sp. The leaves were inoculated with PBS buffer $\left(140 \mathrm{mM} \mathrm{NaCl}, 2.5 \mathrm{mM} \mathrm{KCl}, 10 \mathrm{mM} \mathrm{Na}_{2} \mathrm{HPO}_{4}, 1.5 \mathrm{mM} \mathrm{KH}_{2} \mathrm{PO}_{4} \mathrm{pH}^{7.4}\right)($ a) or B. gladioli (approximately 500 cells per wound) (b); B. seminalis TC3.4.2R3 (approximately 500 cells per wound) (c); B. gladioli (approximately 500 cells per wound) and B. seminalis TC3.4.2R3 (approximately 500 cells per wound) (1:1) (d); B. gladioli (approximately 500 cells per wound) and Burkholderia TC3.4.2R3 (approximately 50 cells per wound) (1:0.1) (e); and B. gladioli (approximately 500 cells per wound) and Burkholderia TC3.4.2R3 (approximately five cells per wound) (1:0.01) (f). Photographs were taken 5 days after inoculation.
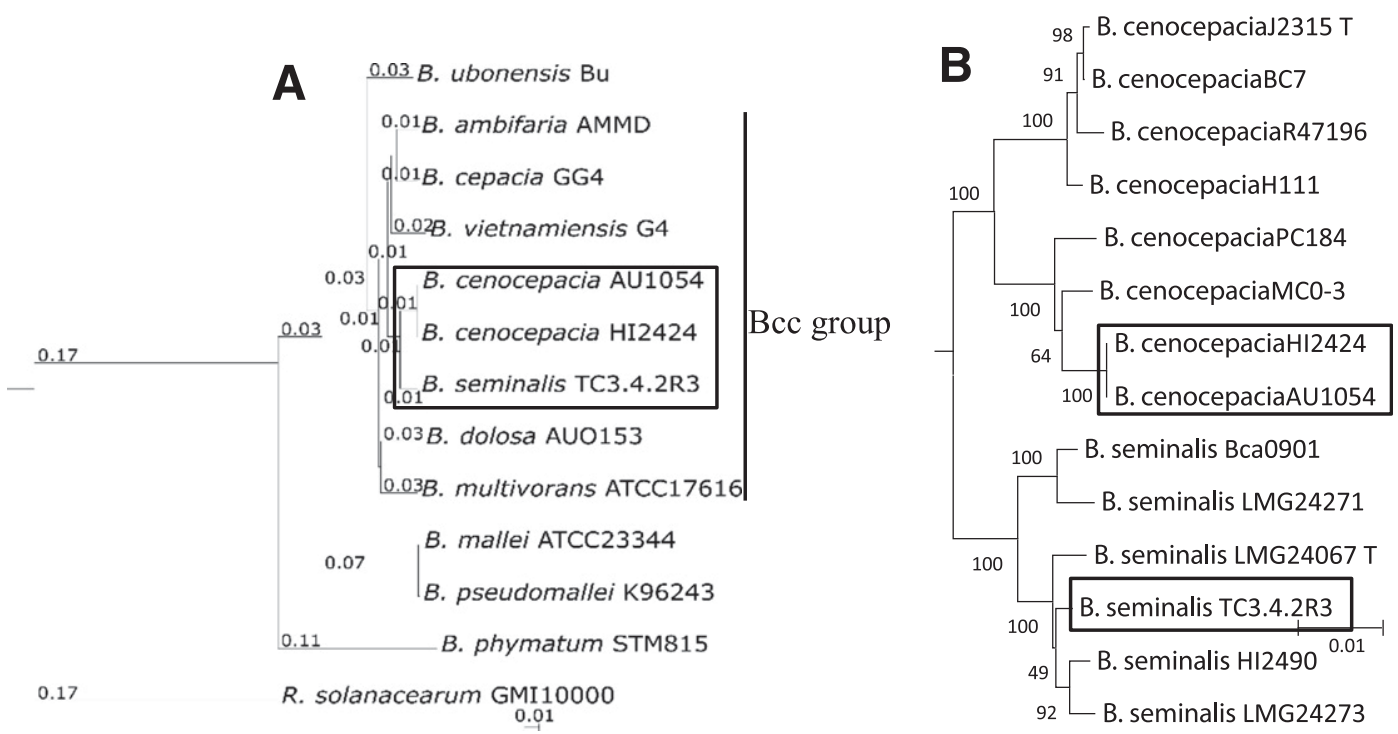

Fig. 3. A, Multigene neighbor-joining tree of representative Burkholderia strains. Translated sequences from 1,055 homologous genes present in B. seminalis TC3.4.2R3, and 13 additional Burkholderia strains were used to generate the tree. Branch lengths greater than zero are indicated and bootstrap values are 100 at all nodes. B, Branch of phylogenetic tree, based on multilocus sequence analysis, showing the relation of TC3.4.2R3 with B. cenocepacia strains (the complete tree is in supplementary materials). 

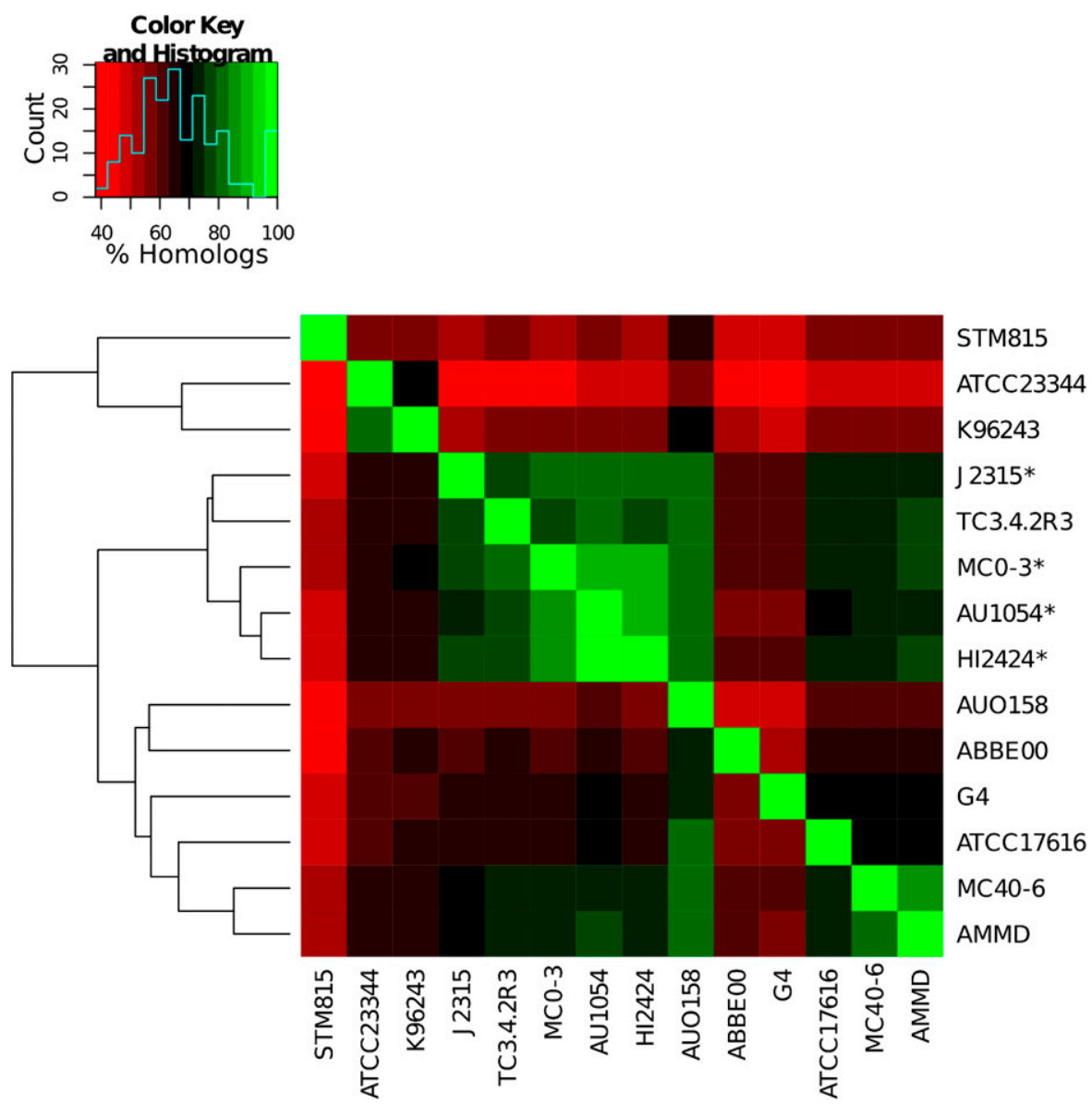

Fig. 4. Heatmap of reciprocally shared gene sequences in Burkholderia strains. Reciprocal blastp analysis was used to identify homologs between all possible pairwise comparisons of genome sequences of 14 representative Burkholderia strains ( $x$ and $y$ axes; asterisks [*] indicates B. cenocepacia strains). The percentage of homologs between each pairwise comparison was normalized relative to genome size and displayed as a heatmap (green $=$ higher percentage of the genes in one genome have a homolog in the genome sequence being compared; red = lower percentage of the genes in one genome have a homolog in the genome sequence being compared). The distance between pairwise comparisons is displayed on the left as a dendrogram.

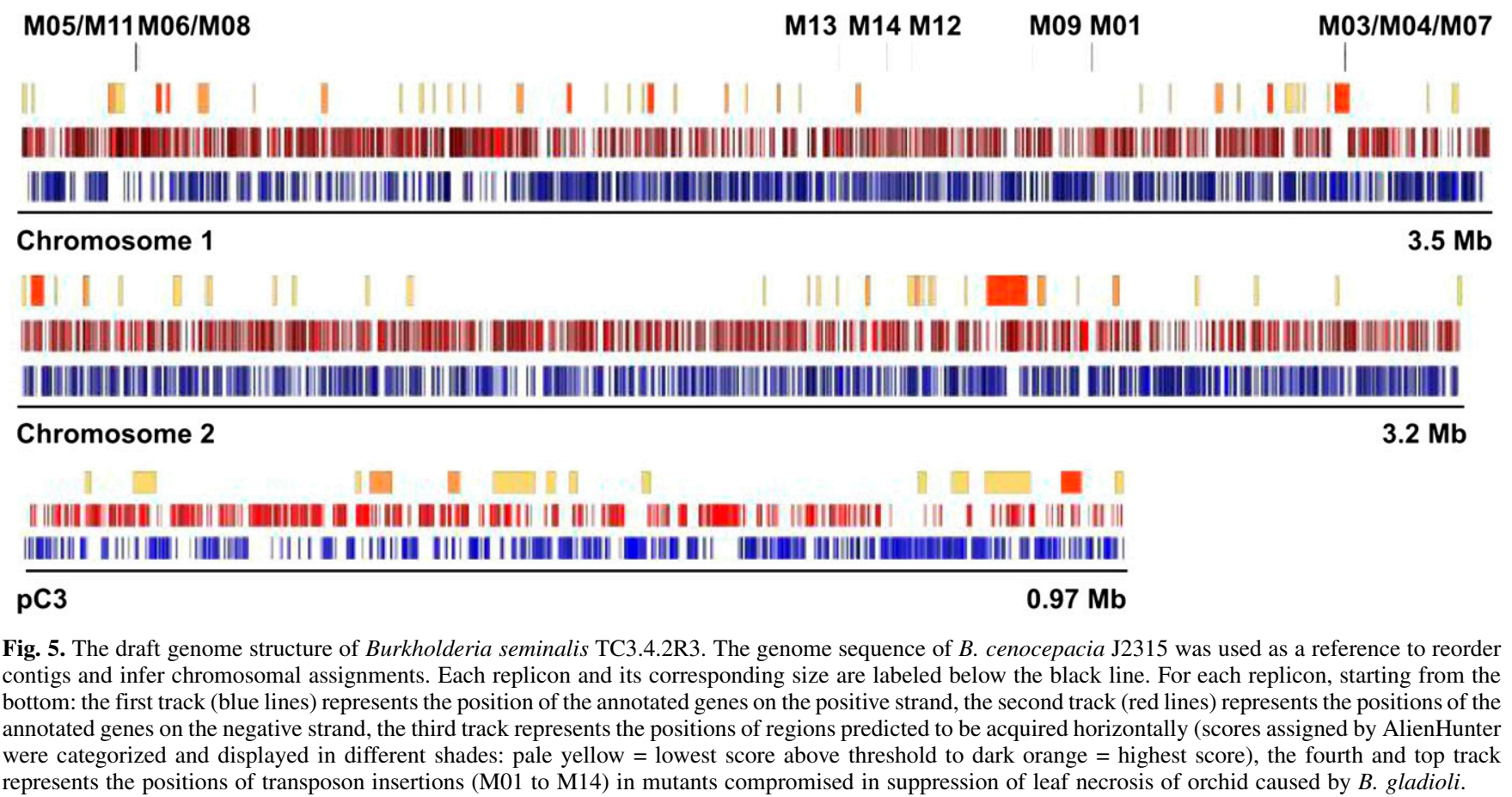


regions showed a skewing toward the COG categories of "Transcription", "Cell wall/membrane/envelope biogenesis", and "Defense mechanisms", relative to analysis of all genes in the TC3.4.2R3 genome. Manual inspection of annotated functions revealed no genes within the genomic islands that are known to function in biological control of plant diseases or have obvious and direct roles in promoting bacterial fitness in a plant host or microbial community.

\section{B. seminalis TC3.4.2R3 has genes encoding for traits potentially involved in plant-microbe interactions.}

To identify genes potentially involved in the interaction of B. seminalis TC3.4.2R3 with the host plant or other microorganisms, we manually surveyed the genome for the presence of loci that are associated with plant disease suppression or plant growth promotion in other bacteria.

Metabolism of phytohormones. Some plant-associated bacteria directly influence plant growth and development by producing or degrading plant hormones (Lugtenberg and Kamilova 2009). Indole-acetic acid (IAA) is the primary auxin in plants, controlling many important physiological processes, and IAA production by plant-associated bacteria can have profound effects on plant growth and development (Spaepen et al. 2007). B. seminalis TC3.4.2R3 is known to produce IAA (Luvizotto et al. 2010) and candidate genes that could encode enzymes in three alternative IAA biosynthetic pathways are present in the genome (Supplementary Fig. S3). Ethylene, a second plant hormone, is synthesized in the plant from the precursor aminocyclopropane-1-carboxylic acid (ACC) and decreasing plant ethylene levels through ACC deaminase production is an important mechanism by which Burkholderia spp. promote plant growth (Glick 2014). The genome of B. seminalis TC3.4.2R3 carries acdS (Bsem_03577), which encodes a putative ACC deaminase. This gene is present in many Burkholderia species, in which it is typically linked to $a c d R$, which encodes a leucine-responsive transcriptional regulator in the AsnC family (Bsem_03576). In B. seminalis TC3.4.2R3, however, $a c d S$ is downstream of a gene encoding a LysR-type transcriptional regulator, which suggests that the regulation of acdS could differ among the Burkholderia species.

Secondary metabolite and siderophore biosynthetic gene clusters. B. seminalis TC3.4.2R3 inhibits the growth of the pathogen $B$. gladioli in culture (Table 1), so we screened the genome sequence for the presence of genes encoding for the biosynthesis of antibiotics and other metabolites contributing to plant disease suppression by other biocontrol bacteria (Raaijmakers and Mazzola 2012; Suárez-Moreno et al. 2012). We detected a cluster encoding the complete pathway for the antifungal metabolite pyrrolnitrin (Supplementary Fig. S4) (Hammer et al. 1997). Because pyrrolnitrin is not toxic to bacteria, it is unlikely to contribute to biocontrol of bacterial necrosis caused by $B$. gladioli but could be related to interactions with fungi in or on plants. We also detected a cluster for the biosynthesis and efflux of rhamnolipids (Bsem_0653606543), a large class of amphipathic molecules secreted from bacterial cells that function as surfactants with important roles in motility, cell signaling, and biofilm formation (AbdelMawgoud et al. 2010). Certain rhamnolipids have antibacterial activity (Abdel-Mawgoud et al. 2010). Determining the production and chemical nature of the one or more rhamnoplipids and their role in suppression of orchid leaf necrosis by B. seminalis TC3.4.2R3 were beyond the scope of the present study but are interesting subjects for further investigation,

Siderophore-mediated iron acquisition can contribute to the competitive fitness of bacteria in and on plants and biological control (Loper and Buyer 1991). The B. seminalis TC3.4.2R3 genome has complete clusters for the siderophores pyochelin
(Supplementary Fig. S5) and ornibactin (Supplementary Fig. S6), which are highly conserved in Burkholderia spp. (Thomas 2007). The genome also encodes 21 putative TonB-dependent outer-membrane receptors, a class of proteins that function in uptake of resources from the environment. Among those is an ortholog of $h m u R$, which, along with linked genes for cytoplasmic membrane transport, encodes a haem uptake system that is well conserved in Burkholderia spp. (Thomas 2007). The prevalent role of TonB-dependent receptors in the uptake of ferric-siderophore complexes suggests that this bacterium has the capacity to utilize siderophores produced by other environmental microorganisms to access iron from the environment.

\section{Selection and characterization \\ of mutants deficient in suppression of leaf necrosis.}

We generated a transposon mutant library of $B$. seminalis TC3.4.2R3 and screened it to identify mutants compromised in biocontrol, as a step toward understanding the mechanisms related to suppression of orchid necrosis caused by $B$. gladioli. A total of 3,840 transposon mutants of B. seminalis TC3.4.2R3 were individually coinoculated along with $B$. gladioli into wounds of leaves of 'Aloha Iwanaga'. Twelve mutants compromised in disease suppression were identified; leaves coinoculated with any one of these mutants and B. gladioli exhibited severe necrosis at 5 days after coinoculation. These 12 mutants were then tested for suppression of bacterial necrosis of pseudobulbs and were found to be compromised in control of the symptoms of pseudobulbs as well as leaves. All 12 mutants retained the capacity to inhibit growth of B. gladioli in culture (Table 2). Each of the 12 mutants had only one transposon insertion, as determined from Southern blots (data not shown). The transposon insertions were mapped to the genome of $B$. seminalis TC3.4.2R3 by sequencing the DNA flanking the transposon insertion in each of the 12 mutants. The 12 transposon insertions mapped to a total of eight genes (Table 2), all of which are located in chromosome 1 (Fig. 5). Five mutants had transposon insertions in five distinct genes. Three genes were knocked out in more than one mutant (Table 2), which provides evidence that the screen identified certain loci reproducibly even though the transposon library was not saturated.

Of the eight genes disrupted in one or more of the 12 transposon mutants of TC3.4.2R3 lacking disease suppression, seven genes are highly conserved in Burkholderia spp. but their roles in the inhibition of plant disease symptoms were not previously described. The transposon in mutant M01 mapped to an intergenic region of two highly conserved genes in Burkholderia spp. of unknown function. The transposons in mutants M05 and M11 mapped to Bsem_00261, which is predicted to encode GltB, the large subunit of glutamate synthase, a key enzyme in the nitrogen assimilation network of bacteria (van Heeswijk et al. 2013) responsible for the conversion of glutamine to glutamate. Glutamate is also used as a substrate by some nonribosomal peptide synthases to generate natural products, such as surfactin. In addition, glutamate plays a role in the biosynthesis of complex natural products, such as vicenistatin, incednine, streptolydigin, and butirosin (Walker and van der Donk 2016). In the present study, we speculate that the mutation in $g l t B$ could reduce the glutamate supply for biosynthesis of one or more unknown secondary metabolites that contribute to suppression of orchid necrosis by $B$. seminalis TC3.4.2R3. Two sets of mutants (M06 and M08, M09) have transposon insertions in genes encoding putative membrane transporters in the major facilitator superfamily. Both proteins are highly conserved among Burkholderia spp. but, to our knowledge, substrates transported by homologs of these proteins have not been described. The transposon insertion in 
mutant M12 maps to a gene predicted to encode a fatty acid desaturase, a class of enzymes with key roles in membrane biology and signaling processes of bacteria and other organisms (Aguilar and de Mendoza 2006). Recent studies have shown that a fatty acid desaturase in cyanobacteria participates in a final step of the biosynthesis of a natural product with antimicrobial activity (Micallef et al. 2015; Shishido et al. 2015). Although we have no evidence for this function in TC3.4.2R3, mutant M12 could have lost the ability to synthesize metabolites involved in microbial interactions during plant colonization. Mutant M13 has an insertion in a gene encoding a putative intracellular polyhydroxyalkanoate depolymerase; these enzymes function in the mobilization of endogenous poly(R)hydroxyalkanoic acids, important carbon and energy storage compounds in bacterial cells (Jendrossek and Handrick 2002). Mutant M14 has an insertion in a gene encoding a putative outer membrane protein of unknown function having a D15 antigen domain, which is present in genomes of many gramnegative bacteria. Therefore, nine of the 12 mutants selected based on the loss of biological control activity have transposon insertions in highly conserved genes predicted to encode basic cellular functions, which is consistent with the location of the insertions in chromosome 1 , a replicon that contains many housekeeping genes and is well conserved among sequenced strains of the B. cepacia complex group (Carlier et al. 2014).

Three mutants (M03, M04, and M07) had insertions in a single gene (Bsem_02955) that is not widely conserved in Burkholderia spp. and was potentially acquired via HGT, as determined based on our analysis using Alien Hunter software (Fig. 5). Bsem_02955 encodes the putative glycosyl transferase family protein $\mathrm{WcbE}$ located in the $w c b$ gene cluster in the $B$. seminalis genome. This cluster has genes for the biosynthesis of extracellular polysaccharides of the bacterial capsule, an important determinant in the communication between bacteria and their hosts (Kim et al. 2005; Sim et al. 2010). In B. pseudomallei, the glycosyl-transferase encoded by $w c b \mathrm{E}$ is essential to the biosynthesis of extracellular polysaccharide (Cuccui et al. 2012), but the $w c b E$ mutants of TC3.4.2R3 exhibited mucoid colony morphologies, indicating that they produced the extracellular polysaccharide. The terminal portions of the $w c b$ cluster of $B$. seminalis TC3.4.2R3 are similar to clusters in other Burkholderia spp., but the central regions of the clusters are variable (Fig. 6). Such variations in the $w c b$ gene cluster have been linked to differences in the pathogenic versus saprophytic lifestyles of other Burkholderia spp. (Kim et al. 2005; Sim et al. 2010) and our results support a role for $w s p E$ in plant disease suppression.

Three of the eight genes identified in our mutant screen (Table 2) were mutagenized in more than one mutant. Our sequence analysis showed that the precise location of the transposon insertion was distinct in each of the mutants, indicating that the mutants were not siblings but each arose from a unique transposition event. Unfortunately, we did not have the resources to complement each of the twelve mutants to prove that the single transposon insertion in each mutant caused the loss of disease suppression. For the three genes that were

Table 2. Characteristics of transposon mutants of Burkholderia seminalis TC3.4.2R3 compromised in suppression of orchid necrosis ${ }^{\mathrm{y}}$

\begin{tabular}{|c|c|c|c|c|c|c|c|}
\hline \multirow[b]{3}{*}{ Strain } & \multirow[b]{3}{*}{ Insertion site } & \multirow[b]{3}{*}{ Annotated function } & \multirow{3}{*}{$\begin{array}{l}\text { Suppression of } \\
\text { leaf necrosis }\end{array}$} & \multicolumn{4}{|c|}{$\begin{array}{c}\text { Population size } \\
\left(\log _{10}[\mathrm{CFU}+1] / \text { wound }\right)^{\mathrm{z}}\end{array}$} \\
\hline & & & & \multicolumn{2}{|c|}{ Leaf } & \multicolumn{2}{|c|}{ Pseudobulb } \\
\hline & & & & 6 days & 12 days & 6 days & 12 days \\
\hline M01 & $\begin{array}{r}\text { Bsem_02386 - } \\
\text { Bsem_02387 }\end{array}$ & $\begin{array}{l}\text { Intergenic region (hypothetical protein } \\
\text { with ferritin-like domain and putative } \\
\text { patatin-like phospholipase) }\end{array}$ & - & $4.24 \mathrm{ab}$ & $4.76 \mathrm{ab}$ & $3.68 \mathrm{ab}$ & $6.43 \mathrm{a}$ \\
\hline M03 & Bsem_02955 & Glycosyl transferase family protein $\mathrm{WcbE}$ & - & ND & ND & ND & ND \\
\hline M04 & & & - & 4.76ab & $3.82 \mathrm{abc}$ & $1.35 \mathrm{bc}$ & $3.95 \mathrm{ab}$ \\
\hline M07 & & & - & $4.97 \mathrm{ab}$ & $4.04 \mathrm{abc}$ & $1.17 \mathrm{bc}$ & $4.43 \mathrm{ab}$ \\
\hline M05 & Bsem_00261 & Glutamate synthase, large subunit, GltB & - & ND & ND & ND & ND \\
\hline M11 & & & - & $1.78 b c$ & $2.99 \mathrm{~b}$ & $3.78 \mathrm{ab}$ & $4.27 \mathrm{ab}$ \\
\hline M06 & Bsem_00266 & Major facilitator superfamily protein & - & ND & ND & ND & ND \\
\hline M08 & & & - & $5.46 \mathrm{ab}$ & $4.00 \mathrm{abc}$ & $4.93 \mathrm{a}$ & $0.0 \mathrm{c}$ \\
\hline M09 & Bsem_02255 & Major facilitator superfamily protein & - & $5.02 \mathrm{ab}$ & $5.52 \mathrm{a}$ & $5.18 \mathrm{a}$ & $5.61 \mathrm{a}$ \\
\hline M12 & Bsem_01991 & Fatty acid desaturase & - & $0.0 \mathrm{c}$ & $2.10 \mathrm{c}$ & $0.0 \mathrm{c}$ & $0.0 \mathrm{c}$ \\
\hline M13 & Bsem_01821 & Polyhydroxyalkanoate depolymerase, intracellular & - & $3.50 \mathrm{ab}$ & $3.67 \mathrm{abc}$ & $3.32 \mathrm{ab}$ & $1.02 \mathrm{bc}$ \\
\hline M14 & Bsem_01919 & Surface antigen (D15) & - & 4.40ab & $4.56 \mathrm{ab}$ & $3.81 \mathrm{ab}$ & $2.63 \mathrm{abc}$ \\
\hline TC3.4.2R3 & - & - & + & $5.84 \mathrm{a}$ & $5.01 \mathrm{ab}$ & $5.11 \mathrm{a}$ & $3.74 \mathrm{ab}$ \\
\hline
\end{tabular}

y All strains listed exhibited inhibition of B. gladioli in culture.

${ }^{\mathrm{z}}$ Numbers in the same column followed by the same letter have no statistical difference according to Tukey test $(P<0.05)$. ND $=$ not determined.

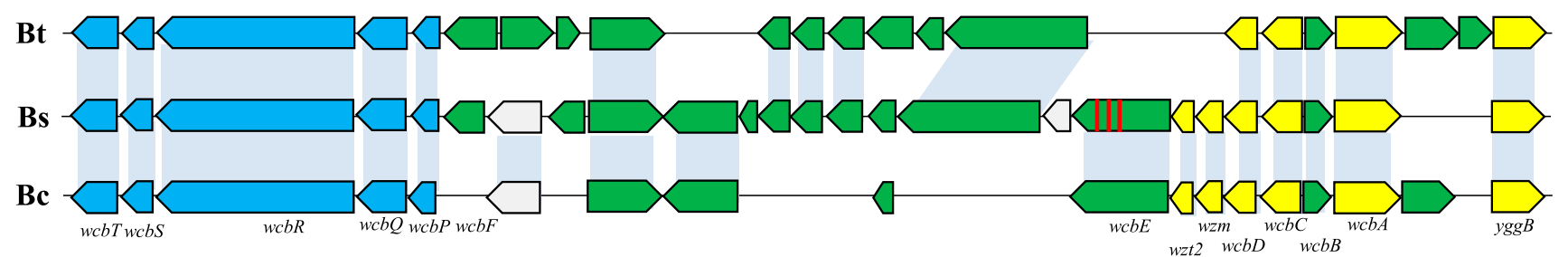

Fig. 6. Comparison of the wcb cluster in Burkholderia thailandensis E264 (Bt), B. seminalis TC3.4.2R3 (Bs), and B. cenocepacea J2315 (Bc). The putative functions of the genes are color coded as follows: X (blue), biosynthesis (green) and transport (yellow), and hypothetical (white). The orthologous genes in the three species are denoted with connecting blocks. The location of the transposon insertions in mutants M03, M04, and M07 of B. seminalis TC3.4.2R3 are demarked with red lines in wcbE (Bsem_02955). 
knocked out in more than one mutant, however, it is very unlikely that a secondary mutation is responsible for the loss of disease suppression. The most likely explanation for the repeated selection of independently generated mutants with a transposon insertion in a shared gene is that the shared gene is responsible for the phenotype. Therefore, this study provides strong evidence that Bsem_02955 (wspE), Bsem_0026 (gltB), and Bsem_00266 contribute to disease suppression. Nevertheless, we recognize that complementation is needed to prove that the transposon insertions in the twelve mutants of this study caused loss of disease suppression.

To determine whether mutants lacking the ability to suppress orchid necrosis could colonize host tissues, we inoculated wounds of leaves or pseudobulbs of 'Aloha Iwanaga' and quantified the population size of selected mutants at 6 and 12 days postinoculation (dpi). One mutant from each of the eight classes was evaluated. Mutants M11 and M12 were reduced in colonization of leaves, whereas the population sizes of the other six mutants did not differ significantly from those of the wild-type strain (Table 2). Mutant M11 showed a delay, relative to strain TC3.4.2R3, in its colonization of orchid leaves but achieved a population size similar to the wild type by 12 dpi. Mutant M12 was not detected in orchid leaves at 6 dpi but could be detected at very low population densities at 12 dpi (Table 2). The growth of both mutants was similar to the wildtype strain in culture (Supplementary Fig. S7), suggesting that the importance of the two genes in fitness of the bacterium was context-dependent; the genes were not necessary for growth in a nutrient-rich medium but had a significant role in colonization of the leaf tissue. Of the two mutants, only M12 differed significantly from the wild-type strain in colonization of pseudobulbs, providing further evidence for the importance of Bsem_01991, which encodes a putative fatty acid desaturase, in colonization of plant tissues. The population sizes of six of the eight mutants in orchid leaves and pseudobulbs did not differ significantly from the wild-type strain, indicating that the six mutants could establish populations in these orchid tissues. Due to the large plant-to-plant variation in population sizes of each strain, however, it is possible that the mutants have reduced fitness that was not detectable in this experiment. Bacterial populations in and on plants are known to be extremely variable (Hirano et al. 1982), so identifying fitness costs associated with individual mutations requires highly replicated and specifically designed experiments, which were beyond the scope of this study. Given the dependence of orchid necrosis suppression on cell density of TC3.4.2R3 (Fig. 2), it is likely that mutants lacking the capacity to colonize plant tissues would not suppress disease as well as the wild-type strain. Reduced colonization was established only for mutants M11 and M12 in this study, but we cannot exclude the possibility that the other mutants that also have transposon insertions in housekeeping genes may have fitness deficiencies that were not detected in our study.

The eight genes identified in our mutant screen could contribute to disease suppression directly, such as through competition with the target pathogen for limited resources. Alternatively, mutations in housekeeping genes are commonly pleiotropic, influencing a myriad of phenotypes expressed by bacterial cells, including the production of secondary metabolites that can suppress pathogens or induce resistance responses in the plant host. While a large number of mutants $(3,840)$ were screened for suppression of orchid leaf necrosis in this study, this number of mutants is not adequate to provide a full coverage of the $B$. seminalis genome. Consequently, we expect that there are many additional genes involved in suppression of orchid necrosis caused by B. gladioli that are not yet known. In this study, we identified eight genes with potential roles in suppression of orchid necrosis, but the mechanisms by which these genes contribute to the interactions between $B$. seminalis TC3.4.2R3 and B. gladioli in or on the host plant remain a subject for future research.

\section{Conclusions.}

In this study, we identified strains of Burkholderia spp. that suppress orchid leaf necrosis caused by B. gladioli. Of the 36 plant-associated strains evaluated, 24 suppressed the disease, indicating that inhibition of this plant pathogen is a common trait in this group of bacteria. We then focused on one biocontrol strain, TC3.4.2R3, which suppressed leaf necrosis on several orchid species. Analysis of the genome sequence of strain TC3.4.2R3 revealed gene clusters for pyrrolnitrin and rhamnolipid biosynthesis and systems for the acquisition of iron through two siderophores and haem. We also identified gene clusters with putative roles in IAA biosynthesis and ethylene degradation via ACC deaminase, opening the possibility that TC3.4.2R3 may interact with plants by altering hormone metabolism. Phylogenetic analysis placed strain TC3.4.2R3 in the species $B$. seminalis, a member of the B. cepacia complex. The close taxonomic relationship of $B$. seminalis to clinical isolates in the B. cepacia complex is likely to limit the development of strain TC3.4.2R3 as a commercial biological control agent, but we pursued studies to reveal mechanisms contributing to the high levels of plant disease suppression exhibited by this bacterium, which could be similar to those of other suppressive species. Eight loci related to suppression of leaf necrosis of orchid were identified by screening a transposon library of B. seminalis TC3.4.2R3 directly on plants. Seven of the eight loci are highly conserved among Burkholderia spp., but one gene is in a genomic island containing a $w c b$ cluster involved in extracellular polysaccharide biosynthesis, a key determinant in bacterial-host interactions in other systems. In summary, this study provided fundamental biological and genomic information and developed molecular tools that can be used in the future to advance understanding of the mechanisms by which bacteria interact on and in plants to suppress disease.

\section{MATERIALS AND METHODS}

\section{Bacterial strains.}

The 36 strains of Burkholderia spp. evaluated in this study were isolated from the rhizosphere or internal tissues of sugarcane (Luvizotto et al. 2010). Strain 11-ORQF04F of $B$. gladioli was isolated from diseased leaves of 'Aloha Iwanaga' collected from a farm in Mogi das Cruzes, São Paulo, Brazil and previously shown to cause necrosis when inoculated into leaves or pseudobulbs of this orchid species (Mano et al. 2015). Burkholderia spp. were grown in 5\% Difco tryptic soy broth (TSB) (Becton, Dickinson and Company) at $28^{\circ} \mathrm{C}$ for $18 \mathrm{~h}$.

\section{Screening of Burkholderia spp. for inhibition} of $\boldsymbol{B}$. gladioli and suppression of orchid leaf necrosis.

The pour plate method was used to assess sugarcane isolates for in vitro inhibition of B. gladioli on Difco tryptic soy agar (TSA). For each inhibition test, three replicates were evaluated and plates were incubated at $28^{\circ} \mathrm{C}$. For assays evaluating suppression of orchid necrosis, strains of Burkholderia spp. were grown, were washed twice with PBS buffer $(140 \mathrm{mM} \mathrm{NaCl}$, $\left.2.5 \mathrm{mM} \mathrm{KCl}, 10 \mathrm{mM} \mathrm{Na}_{2} \mathrm{HPO}_{4}, 1.5 \mathrm{mM} \mathrm{KH}_{2} \mathrm{PO}_{4}, \mathrm{pH} 7.4\right)$, and were resuspended in PBS to a cell density of $10^{5} \mathrm{CFU}$ per milliliter. Leaves of the orchid 'Aloha Iwanaga' were pierced with a sterile toothpick and $5 \mu$ l of cell suspensions were placed on the resulting wound. There were 74 treatements: 
the 36 strains isolated from sugarcane, the 36 strains coinoculated with B. gladioli 11-ORQF04F, B. gladioli 11-ORQF04F alone as a positive control, and PBS alone as a negative control. Each strain was evaluated in a wound on each of three separate plants. The plants were kept at $25^{\circ} \mathrm{C}$ with $85 \%$ relative humidity in a greenhouse for up to 5 days. Each day, plants were visually inspected for the presence of water-soaked, brown lesions surrounding the inoculation site, indicative of infection by $B$. gladioli. The test strain was considered a suppressive strain only if it completely inhibited the necrosis symptoms in all three evaluated plants.

Biocontrol efficacy of strain TC3.4.2R 3 at different inoculum densities and in different orcid varieties was evaluated on leaf fragments. Leaf fragments from a Phalaenopsis sp., Cattleya sp., and Miltonia sp. were pierced with a sterile toothpick and wounds were inoculated with $5 \mu \mathrm{l}$ of cell suspensions of strain TC3.4.2R3 (at $10^{3}, 10^{4}$, or $10^{5} \mathrm{CFU} / \mathrm{ml}$ ) and B. gladioli 11 ORQF04F $\left(10^{5} \mathrm{CFU} / \mathrm{ml}\right)$ and kept at $28^{\circ} \mathrm{C}$ up to 5 days. Five replicate leaf fragments were evaluated for each treatment. The experiment was repeated twice with similar results.

For control of disease in pseudobulbs, strains that inhibited disease symptoms in the previously mentioned assays were placed in a wound with $B$. gladioli on each of three separate plants. The plants were kept at $25^{\circ} \mathrm{C}$ with $85 \%$ relative humidity in a greenhouse for up to 5 days. Each day, plants were visually inspected for the presence of water-soaked, brown lesions surrounding the inoculation site, indicative of infection by $B$. gladioli. Only strains that completely inhibited the disease symptoms in all experiments were considered to be a suppressive strain.

To evaluate the potential of suppressive strains to induce systemic resistance, strains were inoculated in leaves $24 \mathrm{~h}$ prior to inoculating distal leaves with $B$. gladioli. The plants were kept at $25^{\circ} \mathrm{C}$ with $85 \%$ relative humidity in a greenhouse for up to 5 days. Each day, plants were visually inspected for the presence of necrosis surrounding the $B$. gladioli inoculation site. The experiment was repeated twice, using three replicates for each experiment, with similar results.

\section{Generating a transposon mutant library of B. seminalis TC3.4.2R3.}

A library of transposon mutants of B. seminalis TC3.4.2R3 was created using the EZ-Tn5 $<$ R6K $\gamma$ ori/KAN-2 $>$ Tnp transposome kit, according to the manufacturer's instructions (Epicentre Biotechnologies). Mutants were selected on Luria Bertani (LB) agar containing kanamycin $(200 \mu \mathrm{g} / \mathrm{ml})$ and were grown for $72 \mathrm{~h}$ at $28^{\circ} \mathrm{C}$. A total of 3,840 mutants were randomly selected to assay for suppression of orchid necrosis.

Transposon mutants were evaluated for suppression of orchid necrosis caused by $B$. gladioli (strains 11-ORQF04F and 16ORQF03J), using the leaf fragment assay described above. For controls, leaf fragments were inoculated with $B$. gladioli and wild-type Burkholderia sp. strain TC3.4.2R3 (suppressive strain), B. gladioli only (disease control), or PBS buffer (negative control). The experiments were repeated twice, with five replicate leaf fragments per treatment in each experiment. Mutants lacking biocontrol activity in all leaf fragments were tested for biological control of leaf and pseudobulb necrosis of orchid plants in the greenhouse. For this, we used leaves and pseudobulbs of three plants (replicates) for each mutant and wild-type strains.

\section{Assessing bacterial growth}

\section{in culture and population sizes in the host plant.}

To determine whether loss of ability to suppress orchid necrosis could be attributed to reduced growth, one mutant from each of the eight classes was compared with the wild-type strain for growth in a culture medium and in planta. Both analyses were performed in two independent experiments with three replicates each.

For growth curves, bacteria were inoculated in 1:20 strength $\mathrm{TSB}$, were incubated at $28^{\circ} \mathrm{C}$, and were evaluated (optical density at $600 \mathrm{~nm}$ ) each $6 \mathrm{~h}$ for $30 \mathrm{~h}$. For plant colonization, the mutants and wild-type strain were grown in 1:20 strength TSB, were washed twice with PBS, were resuspended in PBS to a cell density of $10^{5} \mathrm{CFU} \mathrm{ml^{-1 }}$, and $5 \mu$ of a cell suspension was placed on a wound caused by piercing a leaf or pseudobulb of the orchid 'Aloha Iwanaga' with a sterile toothpick. The bacteria were reisolated from the plant tissues $(1 \mathrm{~cm}$ from the inoculation site) at 6 and 12 days after inoculation. For this, the plant tissues were macerated and macerates were suspended in sterile PBS buffer. Serial dilutions of the suspensions were placed on 1:20 strength TSA medium amended with kanamycin at $100 \mu \mathrm{g} \mathrm{ml}^{-1}$, were incubated at $28^{\circ} \mathrm{C}$ for $18 \mathrm{~h}$, and the colonies were counted to determine the CFU per gram of orchid tissue.

\section{Nucleic acid preparations.}

Total DNA was isolated from bacteria using an UltraClean microbial DNA isolation kit (MoBio), following the manufacturer's recommendations. The quality and concentration of DNA samples were determined using a nanodrop spectrophotometer (Thermo Scientific).

\section{Identifying the number and location of transposon insertions in mutants of $B$. seminalis TC3.4.2R3.}

The number of transposon insertions in selected mutants was determined from Southern blots. For this, chromosomal DNA was extracted and digested with EcoRI (Fermentas). Restriction fragments were separated by electrophoresis and were transferred to a nylon membrane (Hybond-N; GE Healthcare). The membranes were probed with a digoxigenin (DIG)-labeled probe, which was generated using the polymerase chain reaction (PCR) DIG probe synthesis kit and primers Tn5F (5'GGACGCGATGGATATGTTCT-3') and Tn5R (5'-GATGGTCGGA AGAGGCATAA-3'), which anneal to the R6K replication origin and kanamycin-resistance genes, respectively. Anti-DIG-AP Fab fragments bound to the DIG-labeled probe were visualized with CSPD (Roche Applied Sciences).

To identify the location of transposon insertions, a total of $600 \mathrm{ng}$ of genomic DNA from each mutant was digested with EcoRI, was purified, and was circularized by DNA ligase treatment. The circular DNA was purified (QIAquick PCR purification kit; Qiagen) and was transformed via electroporation into DH5 $\alpha$-pir cells. Transformants were selected on LB agar containing kanamycin $(200 \mu \mathrm{g} / \mathrm{ml})$. Two Escherichia coli colonies from each transformation event were selected for further analysis. Plasmids were extracted from E. coli using the Quick Plasmid miniprep kit PureLink (Invitrogen). The regions flanking the transposon sequence were sequenced using the primers KAN-1 PF-2 (5'-ACCTACAACAAAGCTCTCATCAACC- $\left.3^{\prime}\right)$ and R6KAN RP-2-1 $\left(5^{\prime}\right.$-CTACCCTGTGGAACACCTACATCT- $\left.3^{\prime}\right)$.

\section{Genome sequencing, assembly, and annotation of the genome sequence of Burkholderia sp. strain TC3.4.2R3.}

The genome of B. seminalis TC3.4.2R3 was sequenced using a Genome Sequencer FLX 454 Titanium/Roche (454 Life Sciences). The reads were assembled using Newbler 2.3 (454 Life Sciences). The Mauve Move Contigs function was used to order contigs larger than $500 \mathrm{bp}$, based on the reference genome sequence of B. cenocepacia J2315 (Holden et al. 2009). Prokka v1.5.2 was used to annotate the draft genome sequence (Seemann T. 2014). Gview v1.6 (Petkau et al. 2010) was used to visualize the features of the $B$. seminalis chromosomes. 
Genes in pathways potentially associated with biocontrol were identified based on similarity searches against the nonredundant protein database at GenBank, by BLASTp or by antiSMASH 2.0 (Blin et al. 2013), and were manually annotated using Artemis software (Rutherford et al. 2000). The metabolic pathways were constructed using BioCyc Database Collection (Caspi et al. 2010).

\section{Computational analyses \\ of the Burkholderia sp. strain TC3.4.2R3 genome.}

Sanger sequencing reads were viewed and edited using MEGA 5 (Tamura et al. 2011) and were aligned to the reference genome sequence, using CodonCode Aligner 3.5 (CodonCode Corporation). Coding sequences were identified using ORF Finder and were further evaluated using BLAST tools (BLASTn and BLASTx) from NCBI. Putative operons were identified using Artemis software (Rutherford et al. 2000).

Alien hunter v1.7 (Vernikos and Parkhill 2006) was used to identify regions potentially acquired through HGT. ISsaga (Varani et al. 2011) was used to identify putative insertion sequences. Coding sequences were categorized into COG families using WebMGA (Wu et al. 2011).

MLSA (Baldwin et al. 2005) was done using the concatenated sequences of the housekeeping genes recA (DNA recombinase A), atpD (ATP synthase $\beta$ chain), gltB (glutamate synthase large subunit), gyrB (DNA gyrase subunit $\beta$ ), lepA (GTP binding protein), phaC (acetoacetyl-CoA reductase), and $\operatorname{trp} B$ (tryptophan synthase subunit $\beta$ ). Sequences from type strains were retrieved from the $B$. cepacia complex MLST website (Jolley et al. 2001). B. seminalis TC3.4.2R3 sequences were retrieved from the genome sequence obtained herein. A phylogenetic tree of the concatenated sequences (2,773 bp) was constructed using MEGA 5 software (Tamura et al. 2011), CLUSTAL X alignment (Thompson et al. 1997), neighborjoining clustering (Saitou and Nei 1987), and the Jukes and Cantor model (Jukes and Cantor 1969) for estimating the evolutionary distance. A total of 1,000 bootstraps were performed on the data (Felsenstein 1985).

To construct the heatmap of orthologs, pairwise reciprocal best-hit BLASTp analysis was used to identify homologs (thresholds were $\geq 50 \%$ identity; E value $\leq 1 \times 10^{-7}$ ) between representative Burkholderia strains. Only translated sequences greater than 100 amino acids were examined. The proportion of the total number of shared homologs relative to the total number of coding sequences in each genome sequence was used to create a table for all pairwise comparisons. Using the table as input, the heatmap was constructed using heatmap.2 \{gplots\} in R 2.15.2. A neighbor-joining tree was constructed using Hal (Robbertse et al. 2011) with muscle for the alignment and PHYLIP for the tree. Default settings were used for all software packages, unless indicated.

\section{ACKNOWLEDGMENTS}

This work was supported by grant from Fundação de Amparo à Pesquisa do Estado de São Paulo (FAPESP) (2012/24217-6 and 2013/02124-9) and Fundação de Amparo ao Ensino e Pesquisa (FAEP) (University of Mogi das Cruzes). Work in the J. H. Chang lab is supported in part by Agriculture and Food Research Initiative Competitive Grants Program (grant numbers 2011-67019-30192 and 2012-67013-19392) from the United States Department of Agriculture (USDA) National Institute of Food and Agriculture, National Science Foundation (grant number IOS-1021463), and National Institute of General Medical Sciences of the National Institutes of Health under award number RO1GM104977. Work in the J. E. Loper lab was supported in part by Agriculture and Food Research Initiative Competitive grant 2011-67019-30192 from the USDA National Institute of Food and Agriculture.

\section{LITERATURE CITED}

Abdel-Mawgoud, A. M., Lépine, F., and Déziel, E. 2010. Rhamnolipids: Diversity of structures, microbial origins and roles. Appl. Microbiol. Biotechnol. 86:1323-1336.

Agnoli, K., Schwager, S., Uehlinger, S., Vergunst, A., Viteri, D. F., Nguyen, D. T., Sokol, P. A., Carlier, A., and Eberl, L. 2012. Exposing the third chromosome of Burkholderia cepacia complex strains as a virulence plasmid. Mol. Microbiol. 83:362-378.

Aguilar, P. S., and de Mendoza, D. 2006. Control of fatty acid desaturation: A mechanism conserved from bacteria to humans. Mol. Microbiol. 62: $1507-1514$

Baldwin, A., Mahenthiralingam, E., Thickett, K. M., Honeybourne, D., Maiden, M. C., Govan, J. R., Speert, D. P., Lipuma, J. J., Vandamme, P., and Dowson, C. G. 2005. Multilocus sequence typing scheme that provides both species and strain differentiation for the Burkholderia cepacia complex. J. Clin. Microbiol. 43:4665-4673.

Blin, K., Medema, M. H., Kazempour, D., Fischbach, M. A., Breitling, R., Takano, E., and Weber, T. 2013. antiSMASH 2.0-A versatile platform for genome mining of secondary metabolite producers. Nucleic Acids Res. 41:W204-W212.

Bull, C. T., Weller, D. M., and Thomashow, L. S. 1991. Relationship between root colonization and suppression of Gaeumannomyces graminis var. tritici by Pseudomonas fluorescens strain 2-79. Phytopathology 81: 954-959.

Carlier, A., Agnoli, K., Pessi, G., Suppiger, A., Jenul, C., Schmid, N., Tümmler, B., Pinto-Carbo, M., and Eberl, L. 2014. Genome sequence of Burkholderia cenocepacia H111, a cystic fibrosis airway isolate. Genome Announc. 2:e00298-14

Caspi, R., Altman, T., Dale, J. M., Dreher, K., Fulcher, C. A., Gilham, F., Kaipa, P., Karthikeyan, A. S., Kothari, A., Krummenacker, M. Latendresse, M., Mueller, L. A., Paley, S., Popescu, L., Pujar, A., Shearer, A. G., Zhang, P., and Karp, P. D. 2010. The MetaCyc database of metabolic pathways and enzymes and the BioCyc collection of pathway/genome databases. Nucleic Acids Res. 38:D473-D479.

Chiarini, L., Bevivino, A., Tabacchioni, S., and Dalmastri, C. 1998. Inoculation of Burkholderia cepacia, Pseudomonas fluorescens and Enterobacter sp. on Sorghum bicolor: Root colonization and plant growth promotion of dual strain inocula. Soil Biol. Biochem. 30:81-87.

Coenye, T., and Vandamme, P. 2003. Diversity and significance of Burkholderia species occupying diverse ecological niches. Environ. Microbiol. 5:719-729.

Compant, S., Nowak, J., Coenye, T., Clément, C., and Ait Barka, E. 2008. Diversity and occurrence of Burkholderia spp. in the natural environment. FEMS (Fed. Eur. Microbiol. Soc.) Microbiol. Rev. 32:607-626.

Cuccui, J., Milne, T. S., Harmer, N., George, A. J., Harding, S. V., Dean, R. E., Scott, A. E., Sarkar-Tyson, M., Wren, B. W., Titball, R. W., and Prior, J. L. 2012. Characterization of the Burkholderia pseudomallei K96243 capsular polysaccharide I coding region. Infect. Immun. 80: 1209-1221.

Drevinek, P., and Mahenthiralingam, E. 2010. Burkholderia cenocepacia in cystic fibrosis: Epidemiology and molecular mechanisms of virulence. Clin. Microbiol. Infect. 16:821-830.

Fang, Y., Li, B., Wang, F., Liu, B. P., Wu, Z. Y., Su, T., Qiu, W., and Xie, G. L. 2009. Bacterial fruit rot of apricot caused by Burkholderia cepacia in China. Plant Pathol. J. 25:429-432.

Felsenstein, J. 1985. Confidence limits on phylogenies: An approach using the bootstrap. Evolution 39:783-791

Glick, B. R. 2014. Bacteria with ACC deaminase can promote plant growth and help to feed the world. Microbiol. Res. 169:30-39.

Hammer, P. E., Hill, D. S., Lam, S. T., Van Pée, K.-H., and Ligon, J. M. 1997. Four genes from Pseudomonas fluorescens that encode the biosynthesis of pyrrolnitrin. Appl. Environ. Microbiol. 63:2147-2154.

Hirano, S. S., Nordheim, E. V., Arny, D. C., and Upper, C. D. 1982. Lognormal distribution of epiphytic bacterial populations on leaf surfaces. Appl. Environ. Microbiol. 44:695-700.

Holden, M. T., Seth-Smith, H. M., Crossman, L. C., Sebaihia, M., Bentley, S. D., Cerdeño-Tárraga, A. M., Thomson, N. R., Bason, N., Quail, M. A., Sharp, S., Cherevach, I., Churcher, C., Goodhead, I., Hauser, H., Holroyd, N., Mungall, K., Scott, P., Walker, D., White, B., Rose, H., Iversen, P., Mil-Homens, D., Rocha, E. P., Fialho, A. M., Baldwin, A., Dowson, C., Barrell, B. G., Govan, J. R., Vandamme, P., Hart, C. A., Mahenthiralingam, E., and Parkhill, J. 2009. The genome of Burkholderia cenocepacia $\mathrm{J} 2315$, an epidemic pathogen of cystic fibrosis patients. J. Bacteriol. 191:261-277.

Huang, K. H., Chen, B. Y., Shen, F. T., and Young, C. C. 2012. Optimization of exopolysaccharide production and diesel oil emulsifying properties in root nodulating bacteria. World J. Microbiol. Biotechnol. 28:1367-1373. 
Jacobs, J. L., Fasi, A. C., Ramette, A., Smith, J. J., Hammerschmidt, R., and Sundin, G. W. 2008. Identification and onion pathogenicity of Burkholderia cepacia complex isolates from the onion rhizosphere and onion field soil. Appl. Environ. Microbiol. 74:3121-3129.

Jendrossek, D., and Handrick, R. 2002. Microbial degradation of polyhydroxyalkanoates. Annu. Rev. Microbiol. 56:403-432.

Johnson, K. B., and DiLeone, J. A. 1999. Effect of antibiosis on antagonist dose-plant disease response relationships for the biological control of crown gall of tomato and cherry. Phytopathology 89:974-980.

Jolley, K. A., Feil, E. J., Chan, M. S., and Maiden, M. C. 2001. Sequence type analysis and recombinational tests (START). Bioinformatics 17: 1230-1231.

Jukes, T.H., and Cantor, C. R. 1969. Evolution of protein molecules. Pages 21-132 in: Mammalian Protein Metabolism, H. N. Munro, ed. Academic Press, New York.

Kang, Y., Carlson, R., Tharpe, W., and Schell, M. A. 1998. Characterization of genes involved in biosynthesis of a novel antibiotic from Burkholderia cepacia $\mathrm{BC} 11$ and their role in biological control of Rhizoctonia solani. Appl. Environ. Microbiol. 64:3939-3947.

Keith, L. M., Sewake, K. T., and Zee, F. T. 2005. Isolation and characterization of Burkholderia gladioli from orchids in Hawaii. Plant Dis. 89:1273-1278.

Kim, H. S., Schell, M. A., Yu, Y., Ulrich, R. L., Sarria, S. H., Nierman, W. C., and DeShazer, D. 2005. Bacterial genome adaptation to niches: Divergence of the potential virulence genes in three Burkholderia species of different survival strategies. BMC Genomics 6:174.

Lee, C. J., Lee, J. T., Kwor, J. H., Kim, B. C., and Park, W. 2005 Occurrence of bacterial soft rot of onion plants caused by Burkholderia gladioli pv. alliicola in Korea. Austral. Plant Pathol. 34:287-292.

Lee, Y.-A., and Chan, C.-W. 2007. Molecular typing and presence of genetic markers among strains of banana finger-tip rot pathogen, Burkholderia cenocepacia, in Taiwan. Phytopathology 97:195-201.

Li, B., Fang, Y., Zhang, G., Yu, R., Lou, M., Xie, G., Wang, Y., and Sun, G. 2010. Molecular characterization of Burkholderia cepacia complex isolates causing bacterial fruit rot of apricot. Plant Pathol. J. 26:223-230.

Li, B., Ibrahim, M., Ge, M., Cui, Z., Sun, G., Xu, F., and Kube, M. 2014 Transcriptome analysis of Acidovorax avenae subsp. avenae cultivated in vivo and co-culture with Burkholderia seminalis. Sci. Rep. 4:5698.

Li, B., Liu, B.-P., Yu, R. R., Lou, M. M., Wang, Y. L., Xie, G. L., Li, H.-Y., and Sun, G. C. 2011. Phenotypic and molecular characterization of rhizobacterium Burkholderia sp. strain R456 antagonistic to Rhizoctonia solani, sheath blight of rice. World J. Microbiol. Biotechnol. 27:23052313.

Loper, J. E., and Buyer, J. S. 1991. Siderophores in microbial interactions on plant surfaces. Mol. Plant-Microbe Interact. 4:5-13.

Lu, S. E., Novak, J., Austin, F. W., Gu, G., Ellis, D., Kirk, M., WilsonStanford, S., Tonelli, M., and Smith, L. 2009. Occidiofungin, a unique antifungal glycopeptide produced by a strain of Burkholderia contaminans. Biochemistry 48:8312-8321.

Lugtenberg, B., and Kamilova, F. 2009. Plant-growth-promoting rhizobacteria. Annu. Rev. Microbiol. 63:541-556.

Luvizotto, D. M., Marcon, J., Andreote, F. D., Dini-Andreote, F., Neves, A. A. C., Araújo, W. L., and Pizzirani-Kleiner, A. A. 2010. Genetic diversity and plant-growth related features of Burkholderia spp. from sugarcane roots. World J. Microbiol. Biotechnol. 26:1829-1836.

Mano, E. T., Minami, S. N., Loper, J. E., and Araújo, W. L. 2015. First description of necrosis in leaves and pseudo-bulbs of Oncidium orchids caused by Burkholderia gladioli in São Paulo State, Brazil. Plant Dis 99:1642.

McCulloch, L. 1921. A bacterial disease of gladiolus. Science 54:115-116.

Micallef, M. L., D’Agostino, P. M., Sharma, D., Viswanathan, R., and Moffitt, M. C. 2015. Genome mining for natural product biosynthetic gene clusters in the Subsection V cyanobacteria. BMC Genomics 16: 669

Panhwar, Q. A., Naher, U. A., Radziah, O., Shamshuddin, J., and Razi, I. M 2015. Eliminating aluminum toxicity in an acid sulfate soil for rice cultivation using plant growth promoting bacteria. Molecules 20: 3628-3646.

Parke, J. L., and Gurian-Sherman, D. 2001. Diversity of the Burkholderia cepacia complex and implications for risk assessment of biological control strains. Annu. Rev. Phytopathol. 39:225-258.

Petkau, A., Stuart-Edwards, M., Stothard, P., and Van Domselaar, G. 2010 Interactive microbial genome visualization with GView. Bioinformatics 26:3125-3126.

Raaijmakers, J. M., and Mazzola, M. 2012. Diversity and natural functions of antibiotics produced by beneficial and plant pathogenic bacteria. Annu. Rev. Phytopathol. 50:403-424.
Robbertse, B., Yoder, R. J., Boyd, A., Reeves, J., and Spatafora, J. W. 2011 Hal: An automated pipeline for phylogenetic analyses of genomic data. PLoS Curr. 3:RRN1213.

Rutherford, K., Parkhill, J., Crook, J., Horsnell, T., Rice, P., Rajandream, M. A., and Barrell, B. 2000. Artemis: Sequence visualization and annotation. Bioinformatics 16:944-945.

Ryan, A. D., Kinkel, L. L., and Schottel, J. L. 2004. Effect of pathogen isolate, potato cultivar, and antagonist strain on potato scab severity and biological control. Biocontrol Sci. Technol. 14:301-311.

Saitou, N., and Nei, M. 1987. The neighbor-joining method: A new method for reconstructing phylogenetic trees. Mol. Biol. Evol. 4:406-425.

Sawana, A., Adeolu, M., and Gupta, R. S. 2014. Molecular signatures and phylogenomic analysis of the genus Burkholderia: Proposal for division of this genus into the emended genus Burkholderia containing pathogenic organisms and a new genus Paraburkholderia gen. nov. harboring environmental species. Front. Genet. 5:429.

Schmidt, S., Blom, J. F., Pernthaler, J., Berg, G., Baldwin, A. Mahenthiralingam, E., and Eberl, L. 2009. Production of the antifungal compound pyrrolnitrin is quorum sensing-regulated in members of the Burkholderia cepacia complex. Environ. Microbiol. 11:1422-1437.

Seemann, T. 2014. Prokka: Rapid prokaryotic genome annotation. Bioinformatics 30:2068-2069.

Shishido, T. K., Jokela, J., Kolehmainen, C.-T., Fewer, D. P., Wahlsten, M., Wang, H., Rouhiainen, L., Rizzi, E., De Bellis, G., Permi, P., and Sivonen, K. 2015. Antifungal activity improved by coproduction of cyclodextrins and anabaenolysins in cyanobacteria. Proc. Natl. Acad. Sci. U.S.A. 112:13669-13674.

Sim, B. M. Q., Chantratita, N., Ooi, W. F., Nandi, T., Tewhey, R., Wuthiekanun, V., Thaipadungpanit, J., Tumapa, S., Ariyaratne, P., Sung, W.-K., Sem, X. H., Chua, H. H., Ramnarayanan, K., Lin, C. H., Liu, Y., Feil, E. J., Glass, M. B., Tan, G., Peacock, S. J., and Tan, P. 2010. Genomic acquisition of a capsular polysaccharide virulence cluster by non-pathogenic Burkholderia isolates. Genome Biol. 11: R89.

Smith, K. P., Handelsman, J., and Goodman, R. M. 1999. Genetic basis in plants for interactions with disease-suppressive bacteria. Proc. Natl. Acad. Sci. U.S.A. 96:4786-4790.

Spaepen, S., Vanderleyden, J., and Remans, R. 2007. Indole-3-acetic acid in microbial and microorganism-plant signaling. FEMS (Fed. Eur. Microbiol. Soc.) Microbiol. Rev. 31:425-448.

Suárez-Moreno, Z. R., Caballero-Mellado, J., Coutinho, B. G., MendonçaPreviato, L., James, E. K., and Venturi, V. 2012. Common features of environmental and potentially beneficial plant-associated Burkholderia. Microb. Ecol. 63:249-266.

Tamura, K., Peterson, D., Peterson, N., Stecher, G., Nei, M., and Kumar, S. 2011. MEGA5: Molecular evolutionary genetics analysis using maximum likelihood, evolutionary distance, and maximum parsimony methods. Mol. Biol. Evol. 28:2731-2739.

Thomas, M. S. 2007. Iron acquisition mechanisms of the Burkholderia cepacia complex. Biometals 20:431-452.

Thompson, J. D., Gibson, T. J., Plewniak, F., Jeanmougin, F., and Higgins, D. G. 1997. The CLUSTAL_X windows interface: Flexible strategies for multiple sequence alignment aided by quality analysis tools. Nucleic Acids Res. 25:4876-4882.

Ura, H., Furuya, N., Iiyama, K., Hidaka, M., Tsuchiya, K., and Matsuyama, N. 2006. Burkholderia gladioli associated with symptoms of bacterial grain rot and leaf-sheath browning of rice plants. J. Gen. Plant Pathol. 72: 98-103.

van Heeswijk, W. C., Westerhoff, H. V., and Boogerd, F. C. 2013. Nitrogen assimilation in Escherichia coli: Putting molecular data into a systems perspective. Microbiol. Mol. Biol. Rev. 77:628-695.

Vandamme, P., and Dawyndt, P. 2011. Classification and identification of the Burkholderia cepacia complex: Past, present and future. Syst. Appl. Microbiol. 34:87-95.

Vanlaere, E., Lipuma, J. J., Baldwin, A., Henry, D., De Brandt, E., Mahenthiralingam, E., Speert, D., Dowson, C., and Vandamme, P. 2008. Burkholderia latens sp. nov., Burkholderia diffusa sp. nov., Burkholderia arboris sp. nov., Burkholderia seminalis sp. nov. and Burkholderia metallica sp. nov., novel species within the Burkholderia cepacia complex. Int. J. Syst. Evol. Microbiol. 58:1580-1590.

Varani, A. M., Siguier, P., Gourbeyre, E., Charneau, V., and Chandler, M. 2011. ISsaga is an ensemble of web-based methods for high throughput identification and semi-automatic annotation of insertion sequences in prokaryotic genomes. Genome Biol. 12:R30.

Vernikos, G. S., and Parkhill, J. 2006. Interpolated variable order motifs for identification of horizontally acquired DNA: Revisiting the Salmonella pathogenicity islands. Bioinformatics 22:2196-2203. 
Vial, L., Chapalain, A., Groleau, M. C., and Déziel, E. 2011. The various lifestyles of the Burkholderia cepacia complex species: A tribute to adaptation. Environ. Microbiol. 13:1-12.

Walker, M.C., van der Donk, W. A. 2016. The many roles of glutamate in metabolism. J. Ind. Microbiol. Biotechnol. 43:419-430.

Wu, S., Zhu, Z., Fu, L., Niu, B., and Li, W. 2011. WebMGA: A customizable web server for fast metagenomic sequence analysis. BMC Genomics 12:444

Yara, R., Maccheroni, W., Jr., Horii, J., and Azevedo, J. L. 2006. A bacterium belonging to the Burkholderia cepacia complex associated with Pleurotus ostreatus. J. Microbiol. 44:263-268.

Young, L.-S., Hameed, A., Peng, S.-Y., Shan, Y.-H., and Wu, S.-P. 2013. Endophytic establishment of the soil isolate Burkholderia sp. CC-A174 enhances growth and P-utilization rate in maize (Zea mays L.). Appl. Soil Ecol. 66:40-47.
Yuan, J., Yang, M., Ren, J., Fu, B., Jiang, F., and Zhang, X. 2014. Analysis of genomic characters reveals that four distinct gene clusters are correlated with different functions in Burkholderia cenocepacia AU 1054. Appl. Microbiol. Biotechnol. 98:361-372.

\section{AUTHOR-RECOMMENDED INTERNET RESOURCES}

Burkholderia cepacia complex MLST website: http://pubmlst.org/bcc National Center for Biotechnology Information (NCBI) ORF Finder analysis tool: http://www.ncbi.nlm.nih.gov/gorf/gorf.html

NCBI homepage: http://www.ncbi.nlm.nih.gov

Oregon State University Scholars Archive: http://ir.library.oregonstate.edu/xmlui/handle/1957/55477 